\title{
Grimecolocicich a caicer Multidisciplinary approach in the pelvic relapse of a previously irradiated cervical tumor
}

Daniel Vázquez-Vicente (D) , ${ }^{1}$ Teresa Castellanos, ${ }^{1}$ Alvaro Cabello, ${ }^{2}$ Enrique Chacon, ${ }^{1}$ Jose Angel Minguez, ${ }^{1}$ Luis Chiva (1) ${ }^{1}$

${ }^{1}$ Obstetrics and Gynecology, Clinica Universitaria de Navarra, Madrid, Spain

2Plastic Surgery, Clinica Universitaria de Navarra, Madrid, Madrid, Spain

\section{Correspondence to} Dr Daniel Vázquez-Vicente, Obstetrics and Gynecology, Clinica Universitaria de Navarra, Madrid 28027, Spain; dvazquezv@unav.es

Accepted 11 February 2020 Published Online First 2 March 2020
This educational video shows a step by step approach for anterior infra levator exenteration with colpectomy along with intraoperative radiation for recurrent/persistent cervical cancer in a patient with one kidney. The patient underwent urinary diversion and neovaginal reconstruction.

A 31-year-old woman with a past medical history of systemic lupus erythematosus and congenital absence of the left kidney was diagnosed with a $4 \mathrm{~cm}$ IIA squamous cervical carcinoma in the context of immunosuppressive therapy. Beyond the proximal vaginal involvement, the workup failed to show any extracervical disease.

Standard concomitant chemoradiotherapy resulted in a questionable partial response. Four months after chemoradiation, pelvic magnetic resonance imaging showed a $4.5 \mathrm{~cm}$ persistent cervical mass along with mild right hydronephrosis and vaginal involvement. Positron emission tomography-computed tomography (PETCT) confirmed the metabolic activity of the cervical tumor without demonstrating distant metastases.

In this video the following procedures are shown, highlighting tips for the most complex steps: (Video 1)

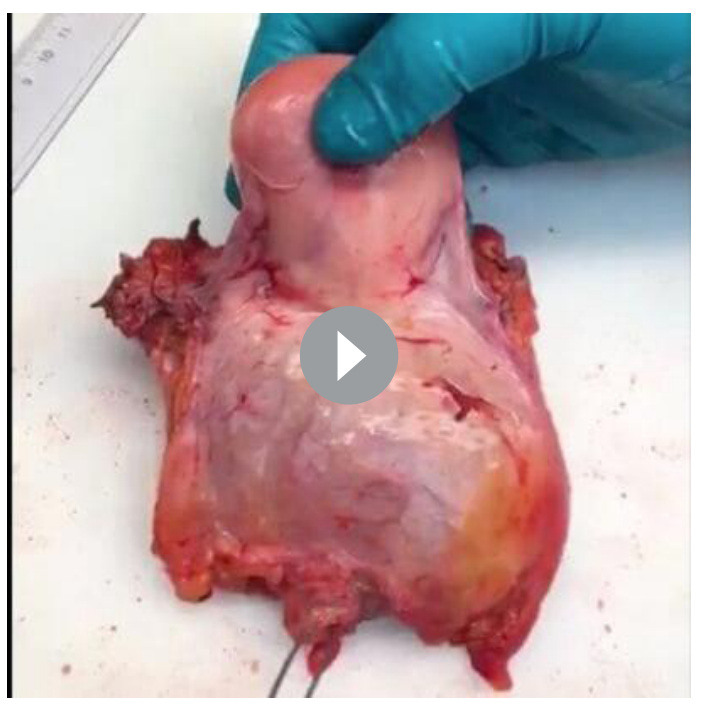

Video 1. Anterior Exenteration
- Anterior exenteration with colpectomy (en bloc resection of the uterus (type $D$ radical hysterectomy), bladder, and vagina).

- Intraoperative radiation with electron therapy over the right pelvic side wall (infiltration of the right parametria).

- Neovaginal reconstruction from a rectus abdominis musculocutaneous flap.

- Urinary diversion was accomplished with an ileal urinary conduit (Bricker procedure) using the only available (right) renal unit.

The final pathological report was a $3 \mathrm{~cm}$ epidermoid cervical tumor with involvement of the superior vagina and right parametria. After an uneventful postoperative period, the patient was discharged on day 10 . Ten months after surgery, the patient has no sign of recurrence.

Pelvic exenteration after radiation is a challenging surgical procedure that may prolong survival in selected patients with local and persistent disease. ${ }^{1}$ Intraoperative radiation allows an extra amount of radiation to be administered in the context of a previous radiated field. Intraoperative radiotherapy after total resection of the recurrence can improve local control rates. ${ }^{2}$

Contributors All authors were involved in the surgery and in the production of the video.

Funding The authors have not declared a specific grant for this research from any funding agency in the public, commercial, or not-for-profit sectors.

Competing interests None declared.

Patient consent for publication Not required.

Provenance and peer review Not commissioned; externally peer reviewed.

Data availability statement There are no data in this work

ORCID iDs

Daniel Vázquez-Vicente http://orcid.org/0000-0002-9618-5606 Luis Chiva http://orcid.org/0000-0002-1908-3251

\section{REFERENCES}

1 Graves S, Seagle B-LL, Strohl AE, et al. Survival after pelvic exenteration for cervical cancer: a national cancer database study. Int J Gynecol Cancer 2017;27:390-5

2 Pilar A, Gupta M, Ghosh Laskar S, et al. Intraoperative radiotherapy: review of techniques and results. Ecancermedicalscience 2017;11:750 